\title{
VARIASI IDENTIFIKASI KUALITATIF FORMALIN PADA IKAN TONGKOL (Euthynnus affinis) DI PASAR TRADISIONAL YOGYAKARTA
}

\author{
(Variation of Formalin Qualitative Identification in Mackerel Tuna \\ (Euthynnus affinis) in Yogyakarta Traditional Market)
}

\author{
Fauziah Novita Putri Rifai ${ }^{a^{*}}$, Rita Maliza ${ }^{a}$ \\ aFakultas Sains dan Teknologi Terapan, Universitas Ahmad Dahlan Yogyakarta, Indonesia \\ * Penulis koresponden: \\ Email: fauziahnovitaputri@gmail.com
}

\begin{abstract}
The use of formalin non-food preservatives in food is now widely used. One of the methods used by fish traders in the preservation process is to use formaldehyde to prevent the process of spoilage and deterioration of fish quality by microorganisms. Formalin can have short and long term effects on health. The formaldehyde content in fish can be identified by qualitative and quantitative tests. Formalin qualitative test methods that have a high degree of accuracy and specificity in fresh fish samples are currently not reported. Therefore, research is conducted which aims to determine the most accurate and appropriate formalin qualitative method for the identification of formaldehyde on mackerel tuna samples. This study uses 5 qualitative test methods including $\mathrm{K}_{10} \mathrm{H}_{8} \mathrm{O}_{8} \mathrm{~S}_{2}$, Tollens, KMnO4 $0.1 \mathrm{~N}$, Schiff, and Fehling on tuna fish samples sold in several Yogyakarta Traditional Markets. Based on the results of the study, the sensitivity level of the 5 formalin qualitative test methods on the 15 highest mackerel tuna samples was the Schiff reagent method.
\end{abstract}

Keywords: formaldehyde, mackerel tuna, qualitative, Fehling method, Schif method

\begin{abstract}
ABSTRAK
Penggunaan pengawet non pangan formalin pada bahan makanan saat ini sudah banyak digunakan. Salah satu cara yang digunakan oleh pedagang ikan dalam proses pengawetan, yaitu dengan menggunakan formalin untuk menghambat terjadinya proses pembusukan dan kemunduran mutu ikan oleh mikroorganisme. Formalin dapat menimbulkan efek jangka pendek dan panjang pada kesehatan. Kandungan formalin pada ikan dapat diidentifikasi dengan uji kualitatif dan uji kuantitatif. Metode uji kualitatif formalin yang memiliki tingkat keakuratan tinggi dan spesifik pada sampel ikan segar saat ini belum dilaporkan. Oleh karena itu dilakukan penelitian yang bertujuan untuk menentukan metode kualitatif formalin yang paling akurat dan sesuai untuk identifikasi formalin pada sampel ikan tongkol. Penelitian ini menggunakan 5 metode uji kualitatif diantaranya asam kromatofat $\left(\mathrm{K}_{10} \mathrm{H}_{8} \mathrm{O}_{8} \mathrm{~S}_{2}\right)$, Tollens, $\mathrm{KMnO} 40,1 \mathrm{~N}$, Schiff, dan Fehling pada sampel ikan tongkol yang dijual dibeberapa Pasar Tradisional Yogyakarta. Berdasarkan hasil penelitian, tingkat sensitivitas dari 5 metode uji kualitatif formalin yang digunakan pada 15 sampel ikan tongkol yang paling tinggi adalah metode pereaksi Schiff.
\end{abstract}

Kata kunci: formalin, ikan tongkol, kualitatif, metode Fehling, metode Schiff 


\section{PENDAHULUAN}

Penggunaan pengawet non pangan pada bahan makanan saat ini sudah banyak digunakan dan yang sering dipakai adalah formalin. Peraturan Menteri Kesehatan Nomor 1168/MenKes/PER/X/1999, formalin merupakan bahan kimia yang penggunaannya dilarang untuk produk makanan. Pemakaian formalin pada makanan dapat menimbulkan efek jangka pendek dan panjang. Efek jangka pendek yaitu keracunan, sakit perut yang akan disertai muntah-muntah, sakit kepala, kejang; sedangkan efek jangka panjang yaitu kerusakan pada sistem saraf pusat dan ginjal (Effendi, 2009).

Ikan tongkol merupakan salah satu hasil perairan yang memiliki harga ekonomis tinggi dan paling banyak dikonsumsi oleh masyarakat di Indonesia. Proses pendistribusian ikan tongkol dari nelayan ke pasar-pasar tradisional membutuhkan waktu yang panjang. Masalah ini akan mengakibatkan proses metabolisme mikroorganisme dan aktivitas enzim dalam tubuh ikan membuat ikan yang mati lebih cepat membusuk dan mengalami kemunduran mutu sebelum sampai ke tangan konsumen (Tunhun et al., 2008). Proses pembusukan oleh mikroorganisme pada ikan bisa diperlambat dengan cara menekan perkembangan mikroba-mikroba pembusuknya (Abbas, 1995).

Terdapat beberapa cara untuk mengidentifikasi formalin pada sampel makanan termasuk ikan dengan menggunakan uji kualitatif, dari beberapa metode yang dapat digunakan untuk uji kualitatif formalin, terdapat 5 metode yang sudah umum digunakan pada sampel ikan yaitu metode asam kromatofat, pereaksi Tollens, KMnO4 0,1 N, pereaksi Schiff, dan pereaksi Fehling. Banyak metode uji kualitatif yang bisa digunakan untuk identifikasi formalin pada sampel makanan, tetapi sampai saat ini belum ada penelitian yang melaporkan metode yang memiliki tingkat keakuratan tinggi dan spesifik pada sampel ikan yang mengandung formalin. Oleh karena itu, tujuan penelitian ini adalah untuk menentukan metode kualitatif formalin yang paling akurat dan sesuai untuk ikan tongkol yang dijual di pasar tradisional Yogyakarta.

\section{Bahan}

\section{BAHAN DAN METODE}

Bahan yang digunakan dalam penelitian ini adalah aquadest (Merck, Jerman), formalin 2\% (Merck, Jerman), formalin 36\% (Merck, Jerman), serbuk asam kromatofat (Merck, Jerman), $\mathrm{H}_{2} \mathrm{SO}_{4}$ (Merck, Jerman), pereaksi Tollens (Merck, Jerman), $\mathrm{KMnO}_{4}$ $0,1 \mathrm{~N}$ (Merck, Jerman), pereaksi Schiff (Merck, Jerman), Fehling A dan Fehling B (Merck, Jerman), alumunium foil.

\section{Pembuatan Kontrol Positif dan Negatif}

Kontrol positif dan negatif menggunakan ikan tongkol segar yang diperoleh dari nelayan di Pantai Congot Purworejo. Ikan tongkol segar direndam dengan $50 \mathrm{ml}$ formalin $2 \%$ selama 30 menit (kontrol positif). Sebanyak 10 gram kontrol positif dan negatif dihaluskan dan ditambahkan $100 \mathrm{~mL}$ aquadest. Larutan didestilasi menggunakan destilator dengan suhu $90^{\circ} \mathrm{C}$. Kemudian diambil destilat sampel tersebut sebanyak 2 $\mathrm{mL}$ dan ditambahkan dengan $1 \mathrm{~mL}$ pereaksi (asam kromatofat, Tollens, $\mathrm{KMnO} 40,1 \mathrm{~N}$, Schiff, Fehling) pada masing-masing metode. Larutan tersebut kemudian dipanaskan dalam waterbath selama 15 menit dan didinginkan dalam suhu ruang \pm 30 menit (metode asam kromatofat, pereaksi Schiff, dan pereaksi Fehling). Kemudian diamati perubahan warna yang terjadi.

\section{Uji Kualitatif}

Uji Kualitatif dilakukan dengan menggunakan sampel ikan tongkol yang diperoleh dari pasar tradisional Yogyakarta, setiap pasar diambil 3 sampel ikan dari setiap penjual ikan yang berbeda dengan tiga kali pengulangan.

1) Metode Asam Kromatofat

Sebanyak 10 gram sampel dihaluskan dan ditambahkan aquadest sebanyak $100 \mathrm{~mL}$. Hasil larutan di destilasi dengan suhu $90^{\circ} \mathrm{C}$. Destilat dimabil sebanyak $2 \mathrm{~mL}$ dan ditambahkan $1 \mathrm{~mL}$ 
asam kromatofat. Kemudian dipanaskan selama 15 menit dan didinginkan dalam suhu ruang selama 30 menit. Sampel yang mengandung formalin akan berwarna merah anggur hingga ungu (lembayung).

2) Metode Pereaksi Tollens

Sebanyak 10 gram sampel dihaluskan dan ditambahkan aquadest sebanyak $100 \mathrm{~mL}$. Hasil larutan di destilasi dengan suhu $90^{\circ} \mathrm{C}$. Destilat dimabil sebanyak $2 \mathrm{~mL}$ dan ditambah $1 \mathrm{~mL}$ pereaksi Tollens. Kemudin di vortex selama 5 detik dan sampel yang mengandung formalin akan menunjukkan perubahan warna menjadi perak metalik dan terdapat endapan berwarna abu-abu

perak.

3) Metode $\mathrm{KMnO}_{4} 0,1 \mathrm{~N}$

Sebanyak 10 gram sampel dihaluskan dan ditambahkan aquadest sebanyak $100 \mathrm{~mL}$. Hasil larutan di destilasi dengan suhu $90^{\circ} \mathrm{C}$. Destilat dimabil sebanyak $1 \mathrm{~mL}$ dan ditambahkan $\mathrm{KMnO}_{4} \quad 0,1 \quad \mathrm{~N}$ sebanyak 3 tetes. Kemudian divortex selama 5 detik dan sampel yang mengandung formalin akan menunjukkan perubahan warna dari ungu tua, menjadi merah bata, kemudian coklat, hingga bening.

4) Metode Schiff

Sebanyak 10 gram sampel dihaluskan dan ditambahkan aquadest sebanyak $100 \mathrm{~mL}$. Hasil larutan di destilasi dengan suhu $90^{\circ} \mathrm{C}$. Destilat dimabil sebanyak $2 \mathrm{~mL}$ dan ditambahkan pereaksi Schiff sebanyak $1 \mathrm{~mL}$. kemudian dipanaskan selama 15 menit dn didinginkan kembali dalam suhu ruang selama 30 menit. Sampel yang mengandung formalin akan menunjukkan perubahan warna menjadi merah keunguan.

5) Metode Fenhling

Sebanyak 10 gram sampel dihaluskan dan ditambahkan aquadest sebanyak $100 \mathrm{~mL}$. Hasil larutan di destilasi dengan suhu $900 \mathrm{C}$. Destilat dimabil sebanyak $2 \mathrm{~mL}$ dan ditambahkan $1 \mathrm{~mL}$
Fehling $A$ dan $1 \mathrm{~mL}$ Fehling $B$. Kemudian divortex selama 5 detik dan warna berubah menjadi biru. Kemudian dipanaskan dalam penangas air diamati perubahan warna yang terjadi selama pemanasan, sampel yang mengandung formalin akan menunjukkan perubahan warna dari biru menjadi oren dan terdapat endapan merah bata.

\section{HASIL DAN PEMBAHASAN}

Penelitian analisis kualitatif pada formalin ini bertujuan untuk mengetahui metode yang paling akurat dalam mendeteksi adanya formalin. Metode yang dapat digunakan dalam mendeteksi adanya formalin yaitu dengan menggunakan asam kromatofat, pereaksi Fehling, pereaksi Schiff, KMnO4 0,1 N, dan pereaksi Tollens. Masing-masing metode memiliki warna standar yang berbeda-beda untuk kontrol positif dan negatif. Metode asam kromatofat pada kontrol positif akan menghasilkan warna ungu lembayung dan kontrol negatif menghasilkan warna bening (Gambar 1a).

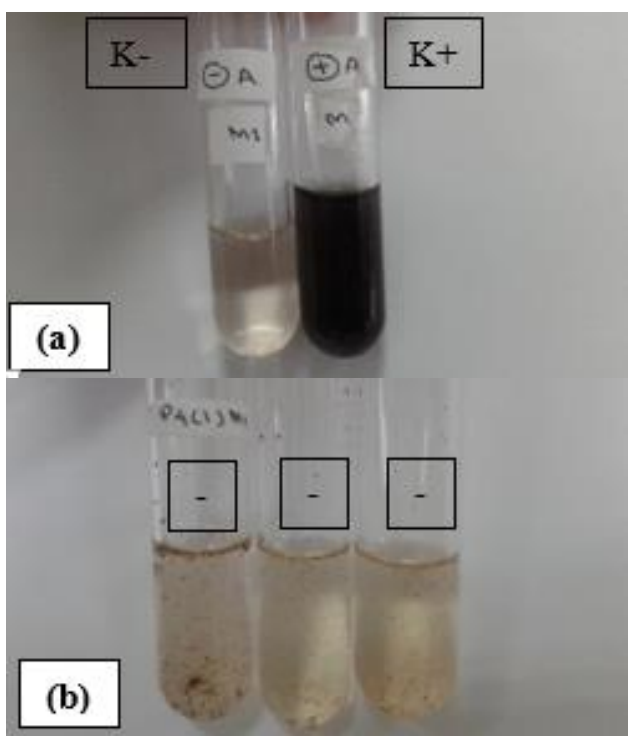

Gambar 1. Hasil uji asam kromatofat (a) kontrol positif; (b) sampel

Uji dengan menggunakan pereaksi tollens pada kontrol positif menghasilkan 
warna abu-abu perak metalik dan negatif menghasilkan warna bening (Gambar 2a).

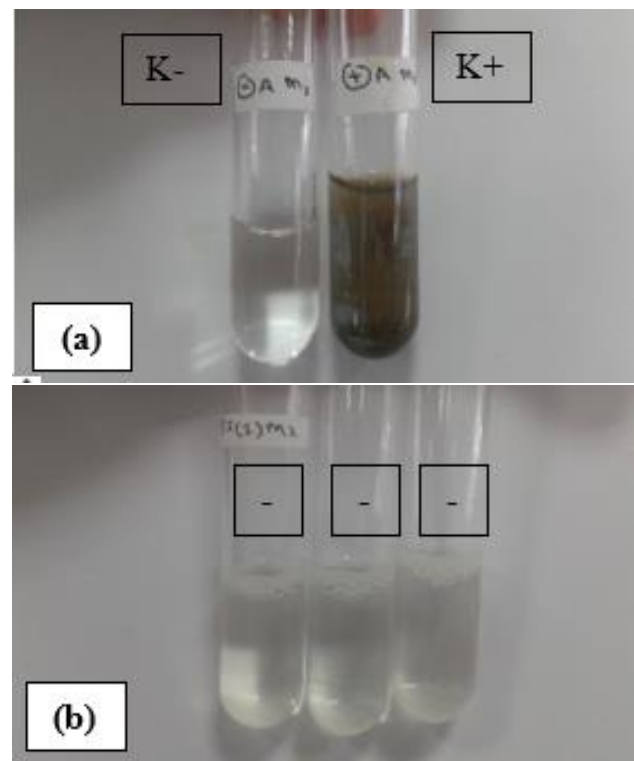

Gambar 2. Uji kualitatif pereaksi tollens (a) kontrol ; (b) sampel

Sedangkan uji KMnO4 pada kontrol positif dan negatif dapat dilihat pada Gambar 3 (a) yang mana kontrol positif menghasilkan warna bening dan kontrol negative menghasilkan warna coklat.

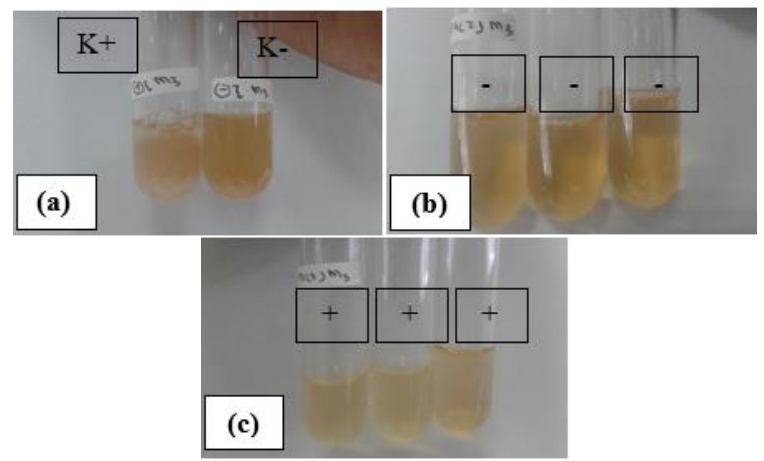

Gambar 3. Uji kualitatif $\mathrm{KMnO}_{4}$ (a) kontrol ; (b) sampel negatif formalin; (c) sampel positif formalin

Uji dengan menggunakan pereaksi Schiff pada kontrol positif dan negatif dapat dilihat pada Gambar 4 (a), kontrol positif menghasilkan warna bening dan kontrol negatif menghasilkan warna ungu.

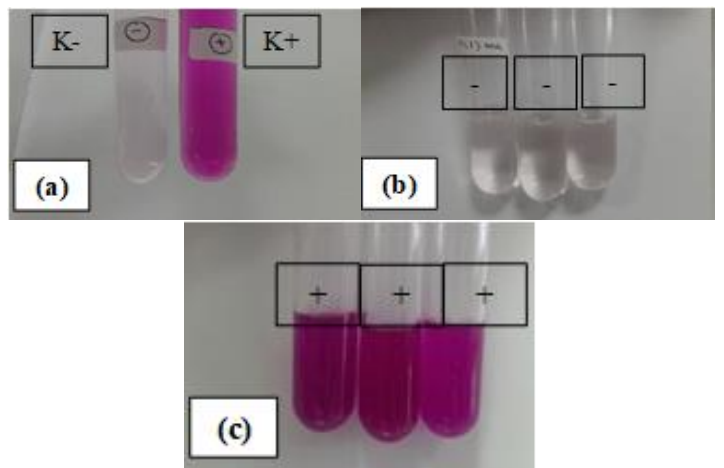

Gambar 4. Uji Kualitatif pereaksi Schiff (a); (b) sampel negatif formalin, (c) sampel positif formalin

Uji dengan menggunakan pereaksi Fehling pada kontrol positif dan negatif dapat dilihat pada Gambar 5 (a), kontrol positif menghasilkan warna bening dan kontrol negatif menghasilkan warna ungu.

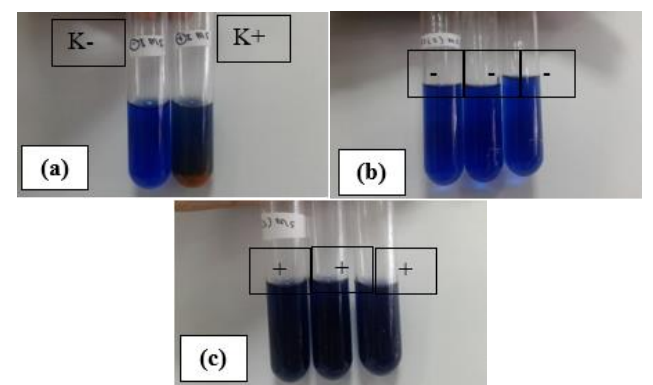

Gambar 5. Uji kualitatif pereaksi Fehling (a) kontrol; (b) sampel negatif formalin; (c) sampel positif formalin

Hasil uji asam kromatofat pada 15 sampel (Tabel 1) menunjukkan hasil negatif yang ditandai dengan warna bening (Gambar 1b). Hasil uji kualitatif negatif formalin dapat terjadi kemungkinan karena 15 sampel ikan tongkol yang diuji memiliki kandungan formalin yang rendah. Berdasarkan penelitian Sucofindo (2009) di pasar tradisional daerah Jakarta menyatakan bahwa asam kromatofat dapat mendeteksi formalin terendah sebesar 2,36 $\mathrm{mg} / \mathrm{kg}$ dan berdasarkan penelitian Hastuti (2010) di pasar daerah Madura menyatakan bahwa asam kromatofat dapat mendeteksi formalin terendah sebesar $29,10 \mathrm{mg} / \mathrm{kg}$. Sehingga dapat dimungkinkan kandungan formalin yang terdapat pada ikan tongkol yang dijual di Pasar Tradisional Yogyakarta 
Tabel 1. Hasi uji kualitatif formalin pada 15 sampel

\begin{tabular}{|c|c|c|c|c|c|}
\hline PASAR & $\begin{array}{l}\text { M1 (Asam } \\
\text { kromatofat) }\end{array}$ & $\begin{array}{c}\mathrm{M} 2 \\
\text { (Tollens) }\end{array}$ & $\begin{array}{c}\text { METODE } \\
\text { M3 } \\
\left(\mathrm{KMnO}_{4}\right)\end{array}$ & $\begin{array}{c}\text { M4 } \\
\text { (Schiff) }\end{array}$ & $\begin{array}{c}\text { M5 } \\
\text { (Fehling) }\end{array}$ \\
\hline \multicolumn{6}{|c|}{ Pasar Kranggan } \\
\hline P1(1) & - & - & + & + & + \\
\hline P1(2) & - & - & - & + & + \\
\hline $\mathrm{P} 1(3)$ & - & - & - & + & + \\
\hline \multicolumn{6}{|c|}{ Pasar Giwangan } \\
\hline $\mathrm{P} 2(1)$ & - & - & - & - & - \\
\hline $\mathrm{P} 2(2)$ & - & - & + & + & + \\
\hline $\mathrm{P} 2(3)$ & - & - & + & + & + \\
\hline \multicolumn{6}{|c|}{ Pasar Beringharjo } \\
\hline P3(1) & - & - & - & + & - \\
\hline P3(2) & - & - & - & + & + \\
\hline P3(3) & - & - & - & + & - \\
\hline \multicolumn{6}{|c|}{ Pasar Prawirotaman } \\
\hline $\mathrm{P} 4(1)$ & - & - & - & + & - \\
\hline$P 4(2)$ & - & - & - & + & + \\
\hline $\mathrm{P} 4(3)$ & - & - & + & + & + \\
\hline \multicolumn{6}{|c|}{ Pasar Lempuyangan } \\
\hline P5(1) & - & - & - & + & - \\
\hline P5(2) & - & - & - & + & - \\
\hline P5(3) & - & - & - & + & - \\
\hline
\end{tabular}

memiliki kandungan formalin yang lebih rendah dari hasil penelitian terdahulu, yaitu dibawah 2,36 mg/kg.

Hasil uji metode Tollens pada 15 sampel (Tabel 1) menunjukkan hasil negatif formalin ditandai dengan warna bening (Gambar 2b). Hasil uji kualitatif negatif formalin pada Tabel 5 dapat terjadi karena rendahnya kadar formalin yang terkandung dalam 15 sampel ikan tongkol sehingga tidak cukupnya gugus aldehid pada formalin yang akan dioksidasi menjadi anion karboksilat. Hasil uji metode $\mathrm{KMnO}_{4} \quad 0,1 \mathrm{~N}$ pada 15 sampel (Tabel 1) menunjukkan adanya 4 sampel yang positif formalin (Gambar 3c). Hal tersebut terjadi karena adanya proses reduksi dari gugus aldehid pada formalin terhadap $\mathrm{KMnO} 40,1$ $\mathrm{N}$ membentuk asam metanoat (Febrianti dan Sari, 2016).

Hasil uji metode Schiff pada 15 sampel (Tabel 1) terdapat 14 sampel ikan tongkol yang menunjukkan hasil positif formalin (Gambar 4c) dan satu sampel negatif formalin (Gambar 4b). Pereaksi Schiff digunakan untuk mengikat formalin agar terlepas dari sampel uji, formalin jika bereaksi dengan pereaksi Schiff menghasilkan senyawa kompleks yang berwarna merah keunguan. Semakin intensif warna yang tampak, dapat menggambarkan bahwa formalin yang terkandung dalam sampel semakin banyak (Kusumawati dan Ika, 2004; Widyaningsih dan Erni, 2006).

Hasil uji metode Fehling terdapat 8 sampel yang menunjukkan hasil positif formalin, hal tersebut ditunjukkan dari warna sampel setelah ditetesi Fehling A $1 \mathrm{ml}$ dan Fehling B $1 \mathrm{ml}$ kemudian dipanaskan menggunakan waterbath, terbentuk endapan merah bata pada sampel dan warna berubah menjadi biru keruh (Gambar 5c). Dalam pereaksi Fehling, ion $\mathrm{Cu} 2+$ 
terdapat sebagai ion kompleks. Pereaksi Fehling dapat dianggap sebagai larutan $\mathrm{CuO}$. Dengan larutan glukosa $1 \%$ pereaksi Fehling menghasilkan endapan merah bata, sedangkan apabila digunakan larutan glukosa $0,1 \%$ endapan yang terjadi berwarna hijau kekuningan (Rosida, 2009). Pereaksi Fehling terdiri dari dua larutan yaitu Fehling $\mathrm{A}$ dan Fehling $\mathrm{B}$. Fehling $\mathrm{A}$ adalah larutan CuSO4 dalam air, sedangkan Fehling $\mathrm{B}$ adalah $\mathrm{K}-\mathrm{Na}$ tartarat dan $\mathrm{NaOH}$ dalam air. Pereksi Fehling dibuat dengan mencampurkan kedua larutan tersebut, sehingga diperoleh suatu larutan yang berwarna biru.

Banyaknya sampel yang menunjukkan hasil positif saat di uji dengan menggunakan metode Schiff, hal tersebut menunjukkan bahwa metode Schiff merupakan metode yang paling efektif digunakan untuk uji kualitatif formalin pada sampel ikan tongkol. Suryadi et al., (2008) dalam penelitiannya kadar konsentrasi formalin pada masingmasing sampel ikan tongkol disetiap metode yang menunjukkan hasil positif formalin.

\section{KESIMPULAN}

Berdasarkan data yang didapatkan pada penelitiaan ini metode kualitatif yang paling sensitif digunakan untuk uji formalin pada ikan tongkol yang dijual di pasar tradisional Yogyakarta adalah metode Schiff.

\section{UCAPAN TERIMA KASIH}

Penulis menyampaikan terimakasih kepada, Rita Maliza, Ph.D yang senantiasa memberikan bimbingan, arahan, saran, dan motivasi selama proses penelitian dan penulisan karya ilmiah ini.

\section{DAFTAR PUSTAKA}

Abbas, S.D. 1995. Pakan Ikan Alami. Yogyakarta: Kanisius.

Adawyah, R. 2007. Pengolahan dan Pengawetan Ikan. Jakarta: Bumi Aksara. Ayu, N.S., Diana, A., Fitria, N.F., Mazaya, D., Misdal., Nur, A.M., Nurfadhillah., Ulva, U. 2017. Uji Kandungan Formalin pada Ikan Asin di Pasar Tradisional Kota Banda mengatakan dari beberapa pereaksi yang digunakan untuk mendeteksi kandungan formalin, pereaksi Schiff merupakan pereaksi warna yang paling baik untuk analisis kualitatif formalin karena kemudahan pengamatan dan pelaksanaannya serta memiliki batas deteksi terendah yang dapat dibedakan jelas dengan penglihatan normal. Pemilihan pereaksi Schiff untuk analisis kualitatif disebabkan terbentuknya warna spesifik antara pereaksi dengan formaldehid dengan batas deteksi terendah 0,2 mg/L (Gambar 4). Berdasarkan hasil penelitian, tingkat sensitivitas masing-masing metode dengan formalin pada sampel ikan tongkol yang dijual di Pasar Tradisional Yogyakarta (diurutkan dari sensitivitas tertinggi sampai yang terendah) adalah pereaksi Schiff, pereaksi Fehling, dan KMnO4. Pada penelitian ini tidak dilanjutkan dengan uji kuantitatif, sehingga tidak dapat mengetahui Aceh. Aceh: Prosiding Seminar Nasional Biotik.

Bogdan, R. dan Biklen, S. 1992. Qualitative \& Quantitative Approaches. Thousand Oaks, CA: Sage Publications.

Cahyadi, W. 2012. Analisis \& Aspek Kesehatan Bahan Tambahan Pangan Edisi Kedua. Jakarta: Bumi Aksara. Halaman 134.

Chronicle, D. 2017. Food Safety Officials

Find Cancerous Preservatives in Fish

Samples. India: Lifestyle Health and Wellbeing.

Clark, J. Materi Kimia Sifat Senyawa Organik. www.chem-is-try.org/materikimia/sifat/senyawa/organik (Diakses : 4 Februari 2019)

Compton, B.J dan Purdy, W.C. 1980. The Mechanism of The Reaction Of The Nash And The Sawicki Aldehyde Reagent, Department of Chemistry, McGill University, 801 Sherbrooke St. W., Montreal, P.Q., Canada H3A 2K6.

Depkes RI. 2009. Bahaya zat-zat additif. Buletin Infarkes Edisi V-Oktober 2009. 
Direktorat Jenderal Bina Kefarmasian dan Alat Kesehatan.

Ditjen POM. 1979. Farmakope Indonesia edisi III. Jakarta: Departemen Kesehatan RI.

Djaafar, T.F. dan Rahayu, S. 2007. Cemaran Mikroba Pada Produk Pertanian, Penyakit yang Ditimbulkan dan Pencegahannya. Jurnal Litbang Pertanian, 26 (2), pp. 25-62.

Effendi, M.S. 2009. Teknologi Pengolahan dan Pengawetan Pangan. Bandung: Alfabeta Indonesia. 2015. Teknologi Pengolahan dan Pengawetan Pangan. Bandung: Alfabeta Indonesia.

Fagnani, E., Melios, C.B., Pezza, L., Pezza H.R. 2002. Chromotropic Acid Formaldehyde Reaction In Strongly Acidic Media. The Role Of Dissolved
Oxygen And Replacement Of Concentrated Sulphuric Acid. Instituto De Qui'mica-UNESP, P.O. Box 355. CEP 14801-970 Araraquara. SP. Brazil.

Food Preservatives Committee. 1924. Formaldehyde in Food. British Medical Journal. 2(3320,: 289-290.

Girsang. 2008. Studi Penentuan Daerah Penangkapan Ikan Tongkol Melalui Pemetaan Penyebaran Klorofil-a dan Hasil Tangkapan di Palabuhan Ratu. Bogor: Institut Pertanian Bogor.

Hadiwiyoto, S. 1993. Teknologi Pengolahan Hasil Perikanan. Yogyakarta: Liberty Yogyakarta.

Tunhun, Dusadee, Sombat, K., Mayuree, C., and Nongnuch, R. 2008. Detection of Ilegal Addition of Formaldehyde to Fresh Fish. Bangkok: Faculty of Fisheries, Kasetsart University. 